\title{
Endoscopic Removal of Skull Base Chordoma Type III through Single Skull Base Approach: Our Early Experience
}

\author{
Alam $S^{1}$, Sharif $\mathbf{M S}^{2}$, Halder $R^{3}$, Chaudhary $A^{3}$, Mahbub $A A^{3}$, Bari $S^{3}$, Haque $M^{4}$.
}

Conflict of interest: There is no conflict of interest relevant to this paper to disclose.

Funding Agency: Was not funded by any institute or any group.

Contribution of Authors: Alam S was Principal investigator, Sharif MS help for protocol preparation, Halder R, Chaudhary A, Mahbub AA, Bari S help for data collection and Haque $M$ help for editorial formatting

Copyright: @2019 Bang.JNS published by BSNS. This article is published under the creative commons CC-BY-NC license.

This license permits use distribution (https://creativecommons.orgf/ licences/by-nc/4-0/) reproduction in any medium, provided the original work is properly cited, and is not used for commercial purposes.

Received: 07 February, 2019

Accepted: 21 February, 2019

\begin{abstract}
:
Introduction: Skull base chordomas present with headache, commonly VI cranial nerve palsy or sometimes with lower cranial nerve involvement. Sometimes in neglected case it presents with complete blindness and facial nerve palsy.
\end{abstract}

Case presentation: A 60-year old man presented with headache, visual disturbance progressing to blindness and facial nerve palsy. At first, radiological imaging showed large tumor which eroded his clivus, sella floor and involved both cavernous carotid more on left side,both ethmoid sinus, middle cranial fossa entension with transdural extension posteriorly.

Conclusion: Patients who present with complete blindness and facial nerve palsy, endoscopic excision in a single skull base approach of a skull base chordoma type III is challenging and who developed visual improvement following surgery, has been highlighted in this report.

Key words: Clival, chordoma, skull base, midline, endoscopic endonasal, single stage, Gross total resection, visual improvement.

Bang. J Neurosurgery 2019; 9(1): 57-63

\section{Introduction:}

Chordomas, which are remnants of the notochord, originate from the bone and can occur anywhere along the craniospinalaxis. ${ }^{1}$ It represent only $1 \%$ to $4 \%$ of primary bone tumors, with an age-adjusted incidence rate of 0.08 per 100,000 patient-years. ${ }^{2}$ There is a two fold greater incidence in males and a five fold greater incidence in the white population. The peak incidence occurs in the eighth decade of life, and development of chordomas is quite rare before the age of 40 . One recent, multi-institutional review suggested that anatomic location is evenly divided among the spheno-occipital region (32\%), mobile spine $(32.8 \%)$, and sacrum(29.2\%). 3,4
Chordomas can present a diagnostic challenge due the rare prevalence and a tendency to involve any region within the cranio-spinal axis. Similarly, their location can present a therapeutic challenge, since they may not be amenable to surgical resection. Approximately $25 \%$ to $40 \%$ of these tumors occur in the skull base, where they typically involve the clivus. ${ }^{4,5,6,7}$ While these tumors rarely metastasize to distant sites, they are locally aggressive and tend to recur after surgical resection, 5 year survival was $51 \%$ and 10 year survival was $35 \% .^{8}$ Most commonly, the patient presents with headache, diplopia secondary to $\mathrm{VI}$ cranial nerve paresis and visual changes including blurring or sometimes loss of vision. The patient may

1. Dr. Shamsul Alam, Assistant professor, Department of Neurosurgery, Bangabandhu Sheikh Mujib Medical University, Dhaka, Bangladesh.

2. Dr. Mohammad Sujan Sharif, Chief resident, Department of Neurosurgery, Bangabandhu Sheikh Mujib Medical University, Dhaka, Bangladesh.

3. Dr. Rathin Haldar, Dr. Anil Chaudhury, Dr. Abdullah-Al-Mahbub, Dr. Shahnwaz Bari, resident, Department of Neurosurgery , Bangabandhu Sheikh Mujib Medical University, Dhaka, Bangladesh.

4. Dr. Moududul Haque Associate professor, Department of Neurosurgery, Bangabandhu Sheikh Mujib Medical University, Dhaka, Bangladesh.

Address of Correspondence: Dr. Shamsul Alam, Assistant professor, Department of Neurosurgery, Bangabandhu Sheikh Mujib Medical University, Dhaka, Bangladesh. 
present with multiple lower cranial nerve palsy symptoms such as facial numbness and asymmetry, dysphagia, hoarseness and speech problems. ${ }^{9}$ Finally, large tumors may cause brainstem compression and patients may present with long tract signs and ataxia. Epistaxis as a rare presentation has also been reported. Cerebrospinal fluid (CSF) rhinorrhea has been very rarely described as a presenting symptom. ${ }^{10}$ We present a case report of a patient who presented with headache, visual disturbance progress to complete blindness and facial nerve palsy. ${ }^{11}$

Case presentation : A 60 years old male presented with headache, visual disturbance progressed to complete blindness and facial nerve palsy. Patient was reasonably well 1 year back. Then he noticed drooping of eyelid of his left eye that did not cause visual disturbance initially but gradually progressed to cover his left eye entirely. He had to lift his left upper eyelid to see things.

He also mentions dimness of vision for the same duration which was initially in the form of blurring of vision but progressed over the course of time and for the last 2 months he could not see anything at all. One year prior to his definite surgery he diagnosed but he did not consult any neurosurgeon. After his vision deteriorated and he could not see anything, he was taken to an ophthalmologist who referred him to our center for specific management.

His vital parameter was normal. on examination, higher psychic function with speech normal. Optic nerve examination shows, Visual acuity,bilateral no perception of light, fundus - bilateral primary optic atrophy. There was right sided lateral rectus palsy and left sided medial, superior, inferior rectii and inferior oblique palsy. Pupil bilaterally $5 \mathrm{~mm}$ in size, nonreacting to light (Fig-01).

On imaging CT scan of brain showed large irregular osteolytic, mixed density lesion in sella, parasella, clival region extend upto left middle fossa sphenoid sinus and both ethmoid sinises, erosion of clivus both petrous apex more on left side, sellar floor, ethmoid bones on contrast CT lesion is heterogeneously enhanced (Fig-02).

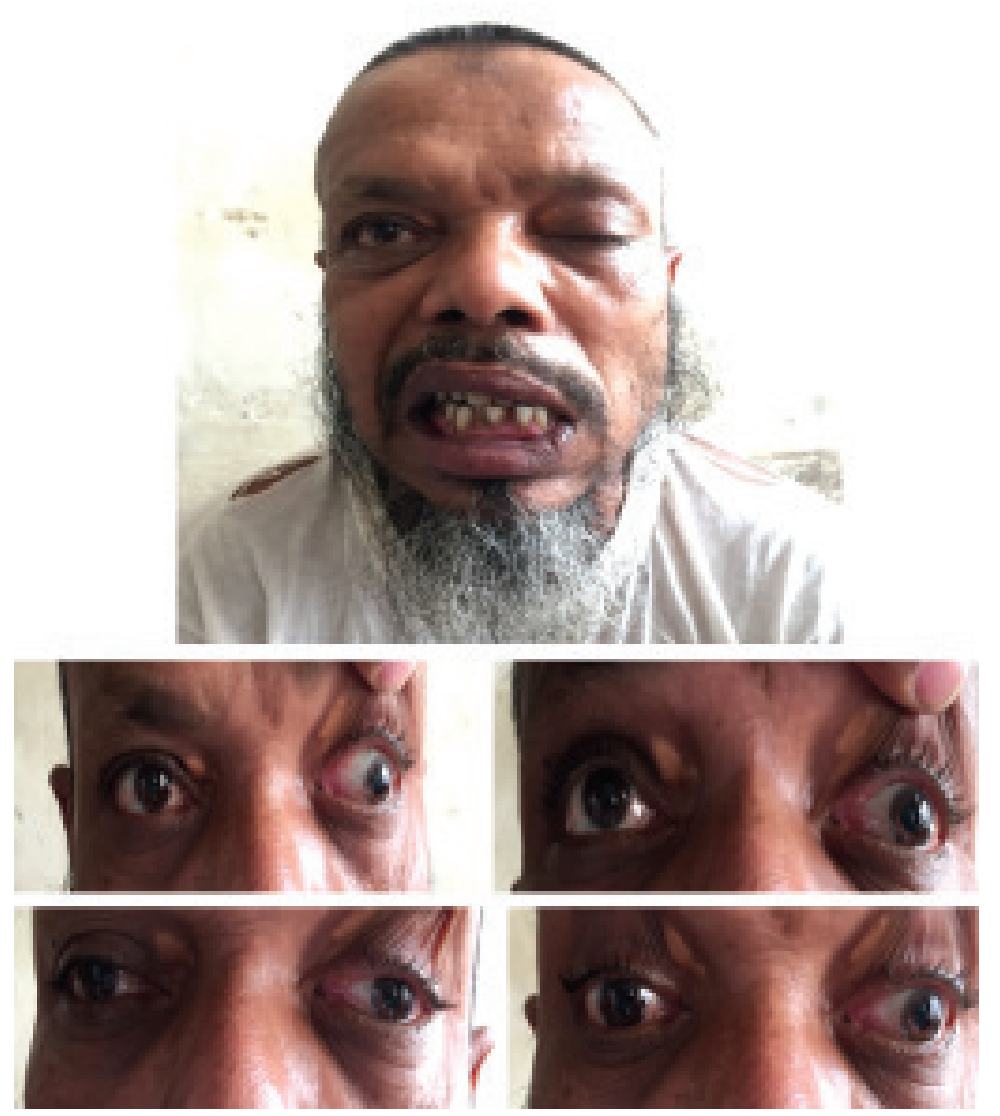

Fig-1: Left sided ptosis (A), left sided medial, superior, inferior rectii and inferior oblique palsy $(B, C, E)$ right sided lateral rectus palsy (D) [With kind permission of the patient] 


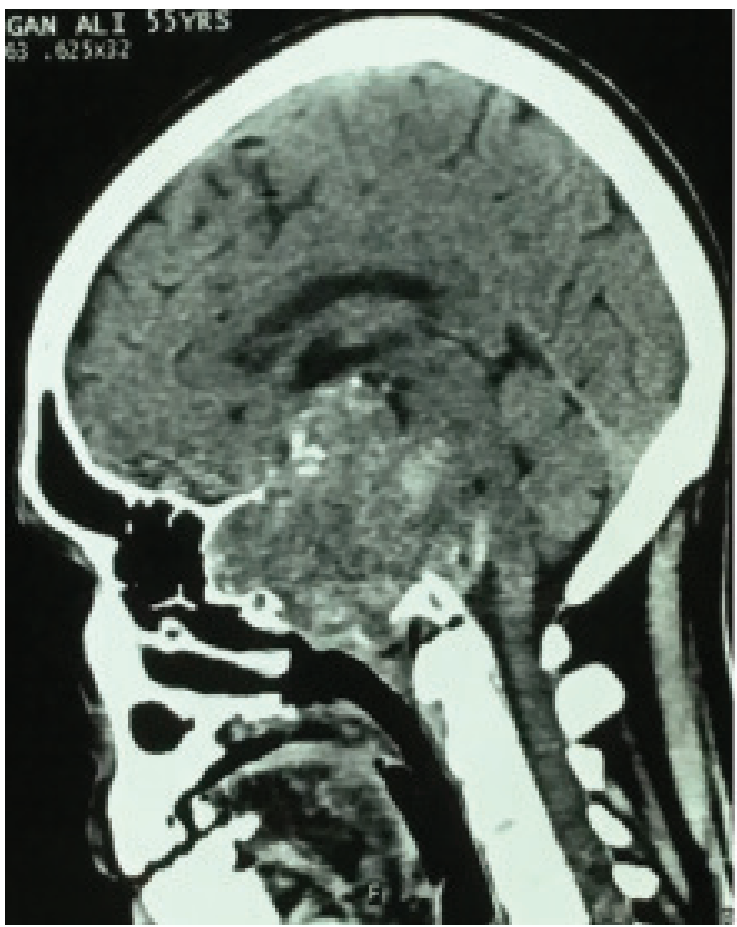

A

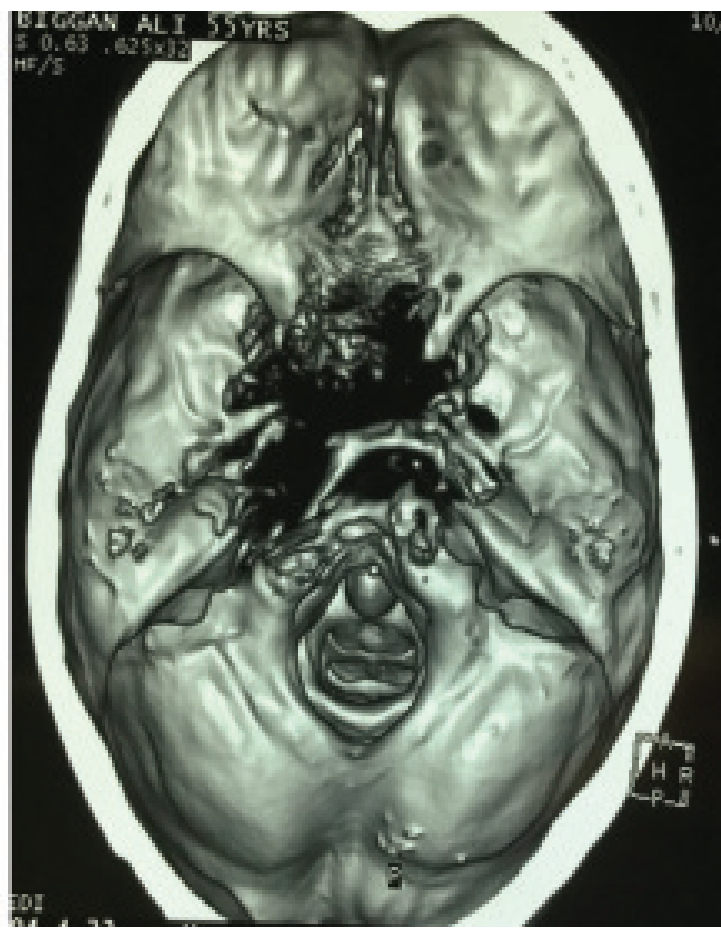

B

Fig.-2: CT scan of brain sagittal section shows, large irregular osteolytic, mixed density lesion in sella, parasella, clival region extend upto left middle fossa sphenoid sinus, on contrast CT lesion is heterogeneously enhanced (A), 3D reconstruction of skull base shows extensive bony erosion (B).

On MRI of brain shows large diffuse lobulated minimally peripherally enhancing mass $(7 \mathrm{~cm} \times 6.5$ $\mathrm{cm}$ ) occupying the sella, parasella, clival region extend upward upto left middle fossa, both cavernous carotid are involved(left carotid encased by tumor) sphenoid sinus and both ethmoid sinuses and some intradural part just anterior to basilar artery, isointense in T1WI, hyperintense in $\mathrm{T} 2 \mathrm{WI}$, no restricted diffusion is noted in DWI (Fig-03).

Mefty et al stated, surgical classification for skull base chordomas based on their patterns of extension through the skull base: Type I are tumors restricted to one compartment of the skull base, defined as a solitary anatomical area (for example, sphenoid sinus, cavernous sinus, lower clivus, or occipital condyle); Type II are tumors that extend to two or more contiguous areas of the skull base and whose radical removal can be achieved using a single skull base approach; and Type III are tumors that extend to several contiguous compartments of the skull base and require two or more skull base procedures to achieve a radical surgical removal. ${ }^{10}$

After proper evaluation, Extended endoscopic endonasal Trans-clival, Trans-planum and Lt. sided
Trans-pterygoid approach and removal of tumour was planed.

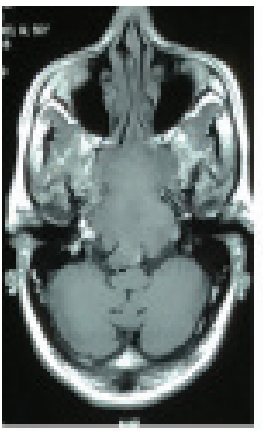

A

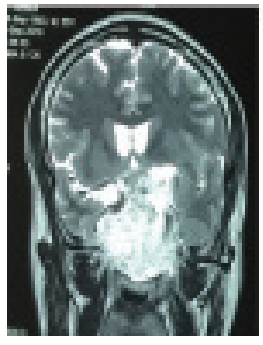

C

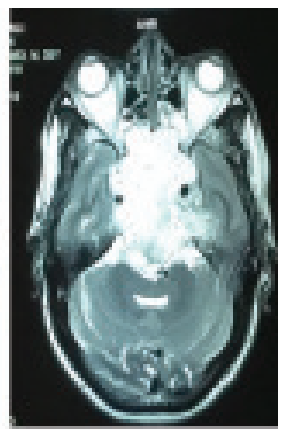

$\mathrm{B}$

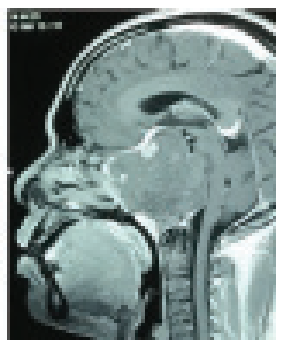

D
Fig.-3: MRI of brain shows isointense in T1WI (A), hyperintense in T2WI, some intradural part just anterior \& right to basilar artery $(B)$, left sided carotid is encased (C), brainstem is compressed severely (D). 


\section{Surgical procedure:}

Patient was positioned in supine, fixed with three pin head fixator, 15-20 degree flexed, 20 degree rotated to right side face towards the surgeon, left thigh exposed for harvesting the fat and fascia lata (Fig:04A). After proper prepping and drepping nasal stage was performed by doing right sided middle turbinectomy, bilaterally inferior turbinectomy, right sided Hadad- Bassagaisteguy vascularized nasoseptal flap was harvested (Fig:04-C), posterior septostomy.

Then sphenoidotomy, left sided pterygoid drilling and medial maxillotomy was performed. As there was extensive skull base erosion noted in 3D reconstruction skull base image (Fig:02-B) minimum drilling was needed with 3-mm coarse diammond burr. Inner cortex was removed with a combination of drilling and kerrison rongeurs.

Tumor was found brownish, somewhere blakish in color, soft suck able, moderately vascular, not firmly attached to carotid, left sided clival and cavernous carotid was decompressed 360 degree. Two-hand suction technique used to provide gentle countertraction in one hand while another suction was used in the other hand to perform internal debulking of the tumor. Somedural invasion seen in left posteriorsuperior region, Dissection especially from brain stem was performed under direct visualization avoiding blind traction. Gross total removal of tumor was achieved. Hemostasis was ensured by gentle bipolar coagulation, gelatin foam (Gelfoam; Upjohn Co., Kalamazoo, Michigan, United States), microfibrillar collagen (Surgicel; Ethicon, Johnson \& Johnson, Somerville, New Jersey, United States), Bony defect was closed by fat, fascia lata, bone chips (Harvested earlier from posterior bony part of nasal septum) and vascularized nasoseptal flap (Fig:06-A).

Postoperative CT Scan showed small residual tumor in right carotid and intradural region(Fig:06-A-C). Post operative recovery was uneventful, patient had no CSF
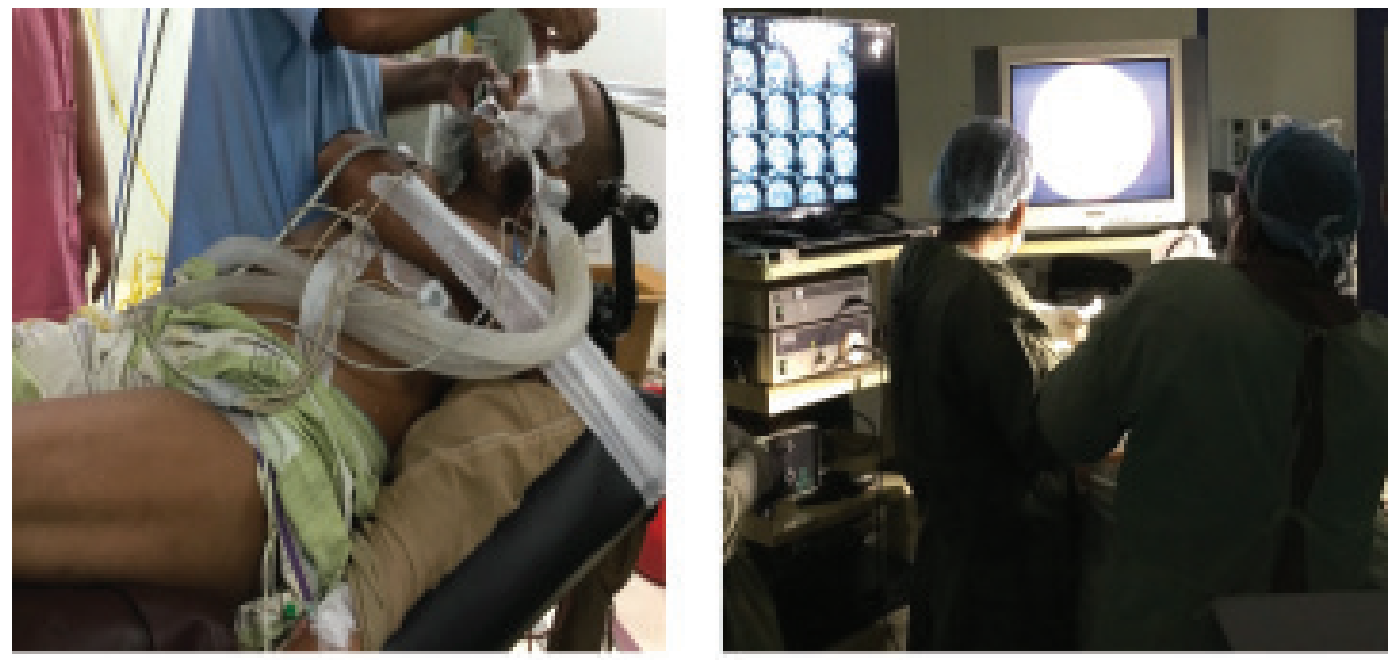

A

B
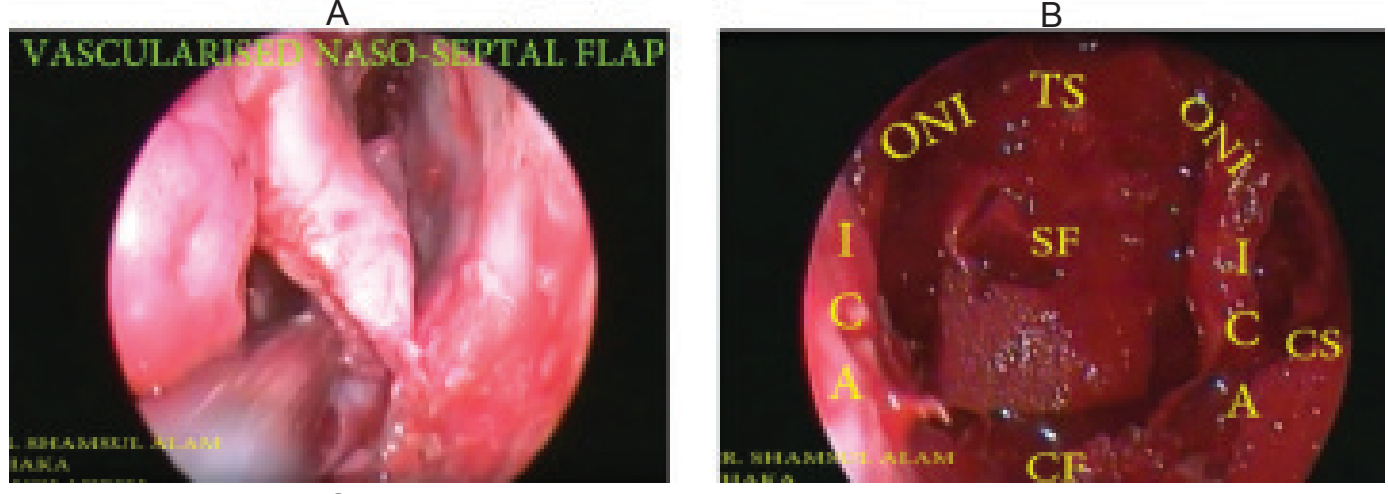

$\mathrm{C}$

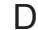

Fig.-4: Supine position, head $20^{\circ}$ flexed and $20^{\circ}$ rotated toward the surgeon (A) OT set up (B), harvesting vascularised naso-septal flap (C), view at the end of tumour removal; ONI-optic nerve impression; TS-tubercullus sella; SF-sellar floor; CS- cavernous sinus; CF-clival fossa; (D). 

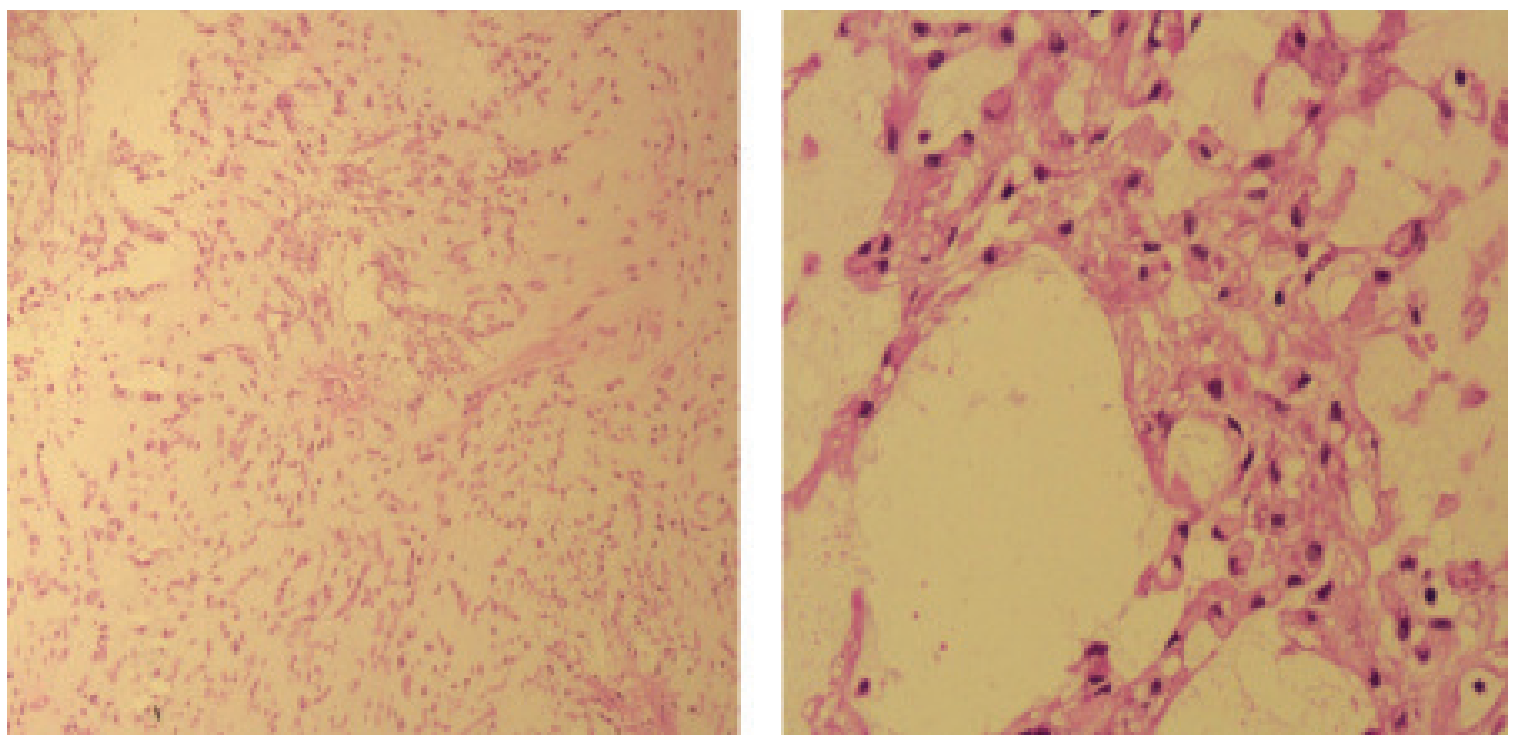

Fig-5: Chordoma characterized by foamy, vacuolated, physaliferous cell grows in distinct nodules

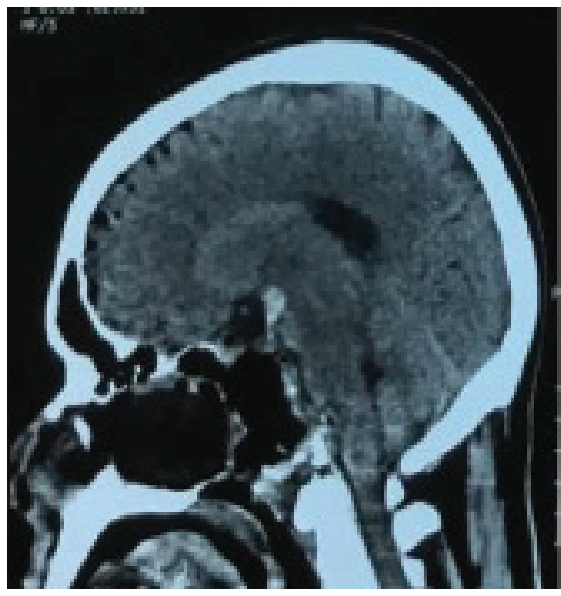

A

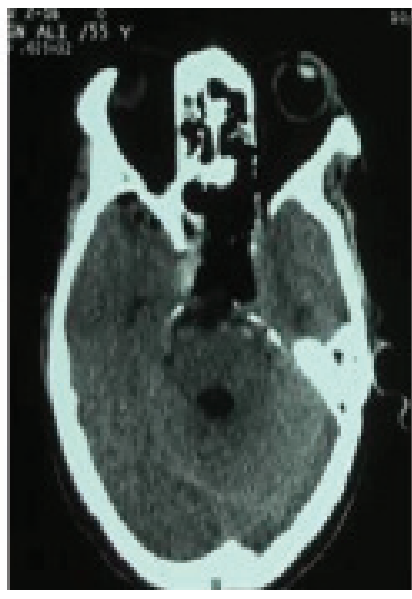

B

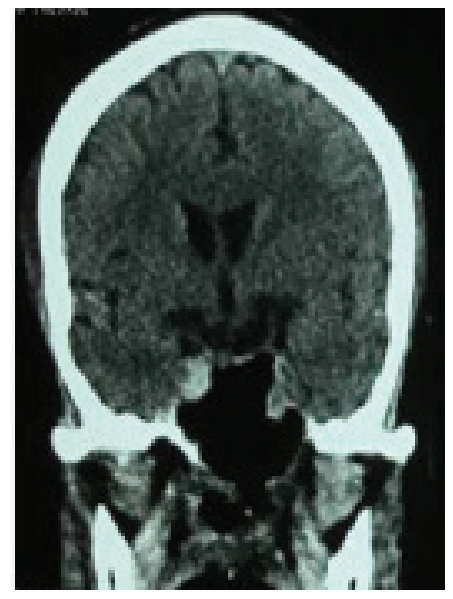

C

Fig-6: Post operative CT scan, Placement of vascularized naso-septal flap, white arrow (A); small residual near right carotid $(B, C)$.

leakage but patient had right upper limb weakness. However, patient developed visual improvement in the form of bilateral hand movement perception.

Histopathology revealed, multiple pieces of soft tissue, lined by respiratory epithelium and pieces of neoplasm. The neoplasm is composed of physaliferous cells within a myxoid stroma. Infiltration of inflammatory cells also present(Fig-05).

\section{Discussion:}

Chordomas were first described by Virchow in 1857 as tumors made up of vacuolated or 'physaliferous' cells derived from rests of embryonic notocord along the midline central nervous system axis.$^{12}$ Chordomas can invade and metastasize to bony structures like the sacrococcyx, skull base and vertebrae. The histological appearance of a chordoma includes pleomorphic cells with dark nuclei and vacuolated or granular cytoplasm set within an abundant myxoid matrix. Neoplastic cells are arranged in epithelial cords separated by mucinous material, which is a classic feature of chordomas. On immunohistochemistry, the cells are positive for S100 protein and epithelial membrane antigen. ${ }^{13}$

The symptoms of a clival chordoma depend mainly on the site of the tumor and the adjacent structures. 
Headache, visual changes and cranial nerve palsies are the most frequent symptoms, thoughrare presentations like CSF rhinorrhea and epistaxis have also been reported. ${ }^{14}$ For diagnosis, it is mandatory to do a CT scan and MRI for all skull base tumors, although there are no reliable diagnostic features that allow differentiation between these tumors. Generally, $\mathrm{MRI}$ is better for defining the exact position of the brainstem and the optic chiasma relative to the tumor with added information about tumor extension into the nasopharynx and cavernous sinus. It also demonstrates the position of the cavernous internal carotid, vertebral and basilar arteries in relation to the tumor. CT is better than MRI in demonstrating tumoral calcification and associated bone destruction. ${ }^{15,16}$

Clival chordomas can be managed by a variety of conventional surgical approaches: transcranial, transsphenoidal, transoropharyngeal and maxillary osteotomy approaches. Transcranial approaches involve brain retraction and have increased risks of cerebral edema and hematoma, apart from carotid, basilar artery and optic nerve trauma. These complications can be greatly reduced with anterior (transnasal, transoral and transfacial) approaches. ${ }^{10,17}$ Currently, endoscopic surgery has opened a new avenue in the management of clival chordomas, not only as a direct surgical access but also by providing an excellent visualization of the clivus and surrounding structures, especially the anterior dura and the basilar artery. The surgical procedures, techniques and selection of the endoscopic surgical strategies for preservation of the vital anatomic structures are described in detail in the literature . $18,19,20,21$

This case report is interesting on several counts. In general, patients with clival chordomas present with headache or cranial nerve palsies.Our patient was hospitalized as a routine case with headache,complete blindness and facial nerve palsy.MRI showed an osteolytic, irregular lesion occupying his clivus that was hyperintense on T2weighted images and hypointense on T1-weighted images, showing mild enhancement with administration of gadolinium .Transnasal transclival endoscopic exploration allowed us en bloc resection of the chordoma.

The two nostrils - four hands technique facilitates better transnasal instrumentation allowing a radical tumor excision and efficient reconstruction of the skull base defect.

The role of radiation therapy has been extremely controversial in the treatment of clival chordomas. Conventional radiation does not appear to have an effect on survival in the study published by Colli and Al-Mefty. ${ }^{22}$ Results of this study indicated that the patient overall survival significantly improved with a radical resection of the tumor combined with postoperative proton beam radiotherapy. There is no study in the literature comparing the results of surgery alone and surgery with postoperative radiotherapy. Finally, with a limited number of cases in the literature, we cannot conclude on the most effective and ideal management of these cases, though most authors agree that complete surgical excision of the tumor mass with an adequate margin provides the best chance for a recurrence-free survival.

\section{Conclusion:}

Patients with a clival chordoma commonly present with headaches, visual changes, cranial nerve palsies .Patient with type III skull chordoma surgery is very challenging that's needs two or more skull base approach .But in this case, removal the tumor carried out by a single endoscopic skull base approach. Moreover, large case series can yield an significant result to establish this route among the surgeons.

\section{References:}

1. Eriksson B, Gunterberg B, Kindblom LG. Chordoma. A clinicopathologic and prognostic study of a Swedish national series. Acta Orthop Scand 1981; 52: 49-58

2. Zhai, Y., Bai, J., Gao, H., Wang, S., Li, M., Gui, S., Li, C. and Zhang, Y., 2017. Clinical features and prognostic factors of children and adolescents with clival chordomas. World neurosurgery, 98, pp.323-328.

3. Crockard, H.A., Cheeseman, A., Steel, T., Revesz, T., Holton, J.L., Plowman, N., Singh, A. and Crossman, J., 2001. A multidisciplinary team approach to skull base chondrosarcomas. Journal of neurosurgery, 95(2), pp.184-189.

4. McMaster, M.L., Goldstein, A.M., Bromley, C.M., Ishibe, N. and Parry, D.M., 2001. Chordoma: incidence and survival patterns in the United States, 1973-1995. Cancer Causes \& Control, 12(1), pp.1-11.

5. Dahlin, D.C. and Maccarty, C.S., 1952. Chordoma. A study of fifty nine cases. Cancer, 5(6), pp.1170-1178.

6. Harvey, W.F. and Dawson, E.K., 1941. Chordoma. Edinburgh medical journal, 48(11), p.713.

7. Tzortzidis, F., Elahi, F., Wright, D., Natarajan, S.K. and Sekhar, L.N., 2006. Patient outcome at long-term followup after aggressive microsurgical resection of cranial base chordomas. Neurosurgery, 59(2), pp.230-237. 
8. Sen, C.N., Sekhar, L.N., Schramm, V.L. and Janecka, I.P., 1989. Chordoma and chondrosarcoma of the cranial base: an 8-year experience. Neurosurgery, 25(6), pp.931-941.

9. O'Connell, J.X., Rosenberg, A.E., Renard, L.G., Liebsch, N.J., Efird, J.T. and Munzenrider, J.E., 1994. Base of skull chordoma. A correlative study of histologic and clinical features of 62 cases. Cancer, 74(8), pp.2261-2267.

10. Al-Mefty, O. and Borba, L.A., 1997. Skull base chordomas: a management challenge. Journal of neurosurgery, 86(2), pp.182-189.

11. Raffel, C., Wright, D.C., Gutin, P.H. and Wilson, C.B., 1985. Cranial chordomas: clinical presentation and results of operative and radiation therapy in twenty-six patients. Neurosurgery, 17(5), pp.703-710.

12. Higinbotham, N.L., Phillips, R.F., Farr, H.W. and Hustu, H.O., 1967. Chordoma. Thirty five year study at memorial hospital. Cancer, 20(11), pp.1841-1850.

13. Rich, T.A., Schiller, A., Suit, H.D. and Mankin, H.J., 1985. Clinical and pathologic review of 48 cases of chordoma. Cancer, 56(1), pp.182-187.

14. Alli, A., Clark, M. and Mansell, N.J., 2008. Cerebrospinal fluid rhinorrhea secondary to ecchordosis physaliphora. Skull Base, 18(6), p.395.

15. Pamir, M.N. and Özduman, K., 2006. Analysis of radiological features relative to histopathology in 42 skull-base chordomas and chondrosarcomas. European journal of radiology, 58(3), pp.461-470.
16. Soo, M.Y., 2001. Chordoma: review of clinicoradiological features and factors affecting survival. Australasian radiology, 45(4), pp.427-434.

17. Rabadán, A. and Conesa, H., 1992. Transmaxillarytransnasal approach to the anterior clivus: a microsurgical anatomical model. Neurosurgery, 30(4), pp.473-482.

18. Stippler, M., Gardner, P.A., Snyderman, C.H., Carrau, R.L., Prevedello, D.M. and Kassam, A.B., 2009. Endoscopic endonasal approach for clival chordomas. Neurosurgery, 64(2), pp.268-278.

19. Koutourousiou, M., Gardner, P.A., Tormenti, M.J., Henry, S.L., Stefko, S.T., Kassam, A.B., Fernandez-Miranda, J.C. and Snyderman, C.H., 2012. Endoscopic endonasal approach for resection of cranial base chordomas: outcomes and learning curve. Neurosurgery, 71(3), pp.614-625.

20. Dehdashti, A.R., Karabatsou, K., Ganna, A., Witterick, I. and Gentili, F., 2008. Expanded endoscopic endonasal approach for treatment of clival chordomas: early results in 12 patients. Neurosurgery, 63(2), pp.299-309.

21. Hadad, G., Bassagasteguy, L., Carrau, R.L., Mataza, J.C., Kassam, A., Snyderman, C.H. and Mintz, A., 2006. A novel reconstructive technique after endoscopic expanded endonasal approaches: vascular pedicle nasoseptal flap. The Laryngoscope, 116(10), pp.1882-1886.

22. Almefty, K., Pravdenkova, S., Colli, B.O., Al Mefty, O. and Gokden, M., 2007. Chordoma and chondrosarcoma: similar, but quite different, skull base tumors. Cancer: Interdisciplinary International Journal of the American Cancer Society, 110(11), pp.2467-2477. 